\title{
Entrepreneurs' Views on the Effectiveness of the Adult Skills Development for Self-Employment in the National Literacy Programme of Namibia
}

\author{
Aletta Tuyenikelao Shikukumwa ${ }^{1}$, Alex Tubawene Kanyimba ${ }^{2 *}$, Rakel Kavena Shalyefu ${ }^{2}$ \\ ${ }^{1}$ Ministry of Education, Sport and Culture, Windhoek, Namibia \\ ${ }^{2}$ Faculty of Education, University of Namibia, Windhoek, Namibia \\ Email: alettashikukumwa@gmail.com, "akanyimba@unam.na,rkshalyefu@unam.na
}

Received 18 May 2016; accepted 26 June 2016; published 29 June 2016

Copyright (C) 2016 by authors and Scientific Research Publishing Inc.

This work is licensed under the Creative Commons Attribution International License (CC BY). http://creativecommons.org/licenses/by/4.0/

(c) (i) Open Access

\section{Abstract}

The Adult Skills Development for Self-employment in the Ministry of Education, Arts and Culture is a partnership venture between the Directorate of Adult Education and the First National Bank of Namibia, which provides a Credit Guarantee Scheme as the common element of contract between these institutions. The aim of this paper is to report on the participating entrepreneurs' views regarding the effectiveness of the Adult Skills Development for Self-employment in the National Literacy Programme in the Khomas Education Region of Namibia. The results show that the project held some benefits for these entrepreneurs in terms of profits generated as well as enabling them to meet living expenses. The training enabled them to record income and calculate expenditure on rent, telephone, water and electricity bills, savings, loan payments, salaries and other cost-related issues. However, knowledge pertaining to how to write a business proposal and conduct market research was still lacking as these issues were not addressed during the training provided. The challenges hampering the effectiveness of the self-employment project are the existence of redtape; poor communication between the Ministry of Education and First National Bank of Namibia; the long route taken to process loans; screening procedures and delays caused by the bank. The possible support measures proposed to improve the effectiveness of the Adult Skills Development for Self-employment relate to the Ministry of Education, Arts and Culture, Ministry of Gender and Child Welfare and the possible involvement of other financial institutions. The recommendations to improve the project's effectiveness involve the Ministry of Education, Arts and Culture, the Directorate of Adult Education and First National Bank of Namibia. These entities need to revisit some of their strategies taking into account the views outlined in this paper.

*Corresponding author.

How to cite this paper: Shikukumwa, A.T., Kanyimba, A.T. and Shalyefu, R.K. (2016) Entrepreneurs' Views on the Effectiveness of the Adult Skills Development for Self-Employment in the National Literacy Programme of Namibia. Open Journal of Social Sciences, 4, 203-212. http://dx.doi.org/10.4236/jss.2016.46021 


\section{Keywords}

\section{Lifelong Education, Adult Learning, Community Education, Entrepreneurship, Employment}

\section{Introduction and Background}

The formal, western and non-formal styles of education in Namibia, as in most other parts of Africa, owe their origin to the efforts of missionaries in the country. However, today both formal and non-formal education systems in Namibia are under the control of the state. Historically, Namibia's education system was designed to reinforce apartheid rather than provide the necessary human resource base to promote equitable, social and economic development. Amukugo [1] and Cohen [2] stated that the Namibian education system was fragmented along racial and ethnic lines, with vast disparities in both the allocation of resources and the quality of education offered [1] [2].

Reports by the Ministry of Education, Arts and Culture have shown that the majority of Namibia's population of 2.1 million depends on agriculture and on the informal sector for subsistence [3] [4]. Societal problems mainly arise from and are reflected by the disparities in income distribution, unemployment and poverty [3] [5]. Sixty percent (60\%) of the population lives below the poverty threshold. The 2007 estimates of the Central Bureau of Statistics also suggest that $19 \%$ and $20 \%$ of young men and women respectively, aged 25 to 29 years, are unemployed. In rural areas, the average unemployment rate is $40 \%$ compared to $30 \%$ in urban areas [3]-[5].

After gaining independence in 1990, Namibia's new government found the situation unsuitable for meeting its political and economic objectives, and concluded that livelihood skills development, particularly in poor rural and peri urban communities, was critical for the enhancement of the communal subsistence economy and its integration into the mainstream national cash economy, as well as for the improvement of people's living standards. As a result, independence brought about fundamental change, which included the provision of education for all, clearly articulated under Article 20 of the Namibian Constitution, [6] that all persons (including adults) should have the right to education.

It is against this background that the government of Namibia, through the Ministry of Education, Arts and Culture, was mandated to create a Directorate of Adult Education (DAE) to be responsible for all adult educational needs. The DAE was officially launched in September 1992. Five programmes are currently managed by the DAE, namely the National Literacy Programme in Namibia (NLPN), the Adult Skills Development for Self-employment (ASDSE) project, Community Learning and Development Centres (CLDCs), the Family Literacy Programme (FLP) and the Adult Upper Primary Education (AUPE) [7]. All these programmes target outof-school youth as well as illiterate and disadvantaged adults, so that they are enabled to participate effectively in national development. The ASDSE project is advanced in that it has a credit scheme which contains components such as mobilisation, coordination, training, and screening of business plans, granting of loans and mentoring [7]. This requires that structures be created to promote effectiveness of the ASDSE formally.

The objectives of the ASDSE project are to enhance institutional capacity building, offer business management skills and promote the informal sector by exposing potential and existing entrepreneurs to business ethics, banking procedures and the creation of employment. The ASDSE was established in 1998 based on the needs expressed by adult learners of the National Literacy Programme in Namibia (NLPN), through the DAE [8]. It aims to provide a better service to the community by harnessing adult education to create employment and income-generating opportunities [9]. It is also expected to contribute towards national efforts to alleviate poverty by affording small grants (loans) to those who have acquired the basic literacy skills needed for self-employment and employment in both urban and rural areas. This requires that graduates from the literacy programme be trained in entrepreneurial skills to enable them to acquire finance to establish small-scale businesses.

Given the above background, the aim of this study was to explore the entrepreneurs' views of the effectiveness of the ASDSE project in the Khomas Education Region of Namibia. To reach this aim, the study firstly presents the statement of the problem and this is followed by the presentation of the research design and methods. The presentation and interpretation of data ensue, followed by the discussions. Finally, recommendations are put forward to enhance the effectiveness of the ASDSE project. 


\section{Statement of the Problem}

The initial ASDSE project is a partnership project between the DAE and FNB, the latter which provides a credit guarantee scheme as the common element of contract between these institutions and the participating entrepreneurs. The DAE has trained over 500 small-scale entrepreneurs to empower them with knowledge and skills that could contribute to job creation, income-generation, empowerment opportunities, and the alleviation of unemployment [10]. There has been a concern among beneficiaries as to whether the ASDSE project is actually effective in achieving the outcomes for which it was established [11]. Therefore, this study attempted to investigate how the entrepreneurs perceived the project in terms of its effectiveness over the past three years. The following questions were addressed to facilitate understanding of the research:

- What are entrepreneurs' views on the effectiveness of the ASDSE project in terms of profit generated from business activities?

- What are entrepreneurs' views on the effectiveness of the ASDSE project in terms of its contribution to poverty alleviation?

- What are entrepreneurs' views on the effectiveness of the ASDSE project in terms of knowledge and skills required from the training programme?

- What are entrepreneurs' views on the challenges to the effectiveness of the ASDSE project?

- What are entrepreneurs' views on the possible support measures required to improve the effectiveness of the ASDSE project?

\section{Research Design and Methods}

The study used a qualitative approach as the data generated were in the form of words, actions and records. A phenomenological design was used. Phenomenological research attempts to understand people's perceptions, perspectives and understanding of a particular situation [12]. A phenomenological approach was therefore used in order to allow the researchers to ascertain and record the entrepreneurs' perspectives on the research questions. According to Lodico, Spaulding and Voegtle [13], a phenomenologist's role is to listen to all participants, to establish the way they perceive reality about the subject under study, as well as their personal experiences, attitudes and emotions.

\subsection{Population and Sampling}

The population for this study consisted of a selection of 20 ASDSE entrepreneurs in the Khomas region who received training and loans from the Ministry of Education through the FNB of Namibia loan scheme.

The researchers used purposive sampling to select the region included in the study, namely the Khomas region that was geographically closer to their places of work. The Khomas region consists of ten constituencies. The participants for this study were drawn from five of these constituencies, namely John Pandeni, Moses Garoeb, Samora Machel, Greenwell Matongo and Katutura East. The researchers were interested in those constituencies where they had participated in the training of entrepreneurs.

A list of all trained entrepreneurs in the five constituencies mentioned above was obtained from the office of the Deputy Director of Lifelong Learning in the Khomas education region. All those selected were entrepreneurs operating from the back yards of their homes. Copies were made of the list and cut into pieces each containing the first name and surname of an ASDSE beneficiary. These papers were placed in five containers according to each constituency before names were selected at random from each container until the required number was obtained.

Four (4) participants were selected from each constituency, that is, a total of 20 entrepreneurs were used as the sample of the study. A list of the selected entrepreneurs was made before administering the interview schedule. Purposive sampling was applied to select participants from the population because the researchers used informants who were knowledgeable and were able to provide the richest insights of the issue addressed during the study [13]-[15]. The sample allowed the researchers a better chance to explore the phenomenon under study in depth [16].

\subsection{Research Instruments and Pilot Study}

The researchers used the interview guide to obtain information from the selected entrepreneurs in the ASDSE project. A pilot study was conducted by one of the researchers with ten beneficiaries in the Khomas region. The 
purpose of the pilot study was to test the reliability of the interview guide and to establish whether the data would be meaningful in relation to the research questions. The results of the pilot study revealed a need to revisit some questions in the instruments. Therefore, repetitive questions were reconsidered and reorganized.

\subsection{Data Collection Procedures, Analysis and Ethics}

The researchers had requested and received an introductory letter from the Faculty of Education of the University of Namibia, after which one of the researchers wrote a letter to the Permanent Secretary of the Ministry of Education to request permission to undertake the study. A copy of the approval letter received from the Permanent Secretary was sent to the Director of the Khomas education region.

Upon arrival in each district, the researchers made an appointment with the District Education Officer in that district to seek their permission and assistance during interviews. One of the researchers personally administered the data collection instruments to participants in the ASDSE project. Informed consent was gained from each of the participants before the interviews were conducted.

The qualitative data were dealt with in an inductive analytical process [17]. The data analysis followed the general procedures of data transcription and organization as well as analysis and incorporating of theory from the literature. The followings steps were taken: the notes that had been written down during the interviews were transcribed and read numerous times in order to identify corresponding themes. The transcribed data were assessed to identify similarities of ideas expressed by the participants. The original ideas were organised and then presented.

To ensure the safety of the participants and prevent violation of their human rights, permission to carry out this study was sought from the Ministry of Education, Arts and Culture through the office of the Director of Khomas Education, Arts and Culture. Informed consent was obtained from each participant after a thorough explanation of the aim of the study and the potential benefits of participating. The participants were assured verbally that for the sake of anonymity and confidentiality their names would not appear anywhere in the research findings. All participants had access to transcriptions and to their transcribed information.

\section{Presentation and Interpretation of Data}

The presentation of data focuses on the entrepreneurs' views of the following: the effectiveness of the ASDSE project in terms of profit generated from business activities, the effectiveness of the ASDSE project in terms of its contribution to poverty alleviation, effectiveness of the ASDSE project in terms of knowledge and skills required from the training programme and the challenges to the effectiveness of the ASDSE project. It also addresses the entrepreneurs' views regarding possible support measures required to improve the effectiveness of the ASDSE project.

\subsection{Entrepreneurs' Views on the Effectiveness of the ASDSE Project in Terms of Profit Generated from Business Activities}

The following responses emerged from the corpus of the entrepreneurs' narratives:

Response 1\# I'm making a profit of one thousand five hundred to two thousand. I'm making more profit and have now expanded my house and built my tailoring workshop, kindergarten and bought a car for the business. Loan allocated was a bit small and that contributed to less profit and fewer saving and less income generated and that did not lead to business satisfaction. The loan allocated to me was twelve thousand.

Response 2\# I'm making a profit of three thousand to three thousand five hundred Namibian dollars. I'm making better profit from the project and by being able to buy more items which my customers need from me. Since the loan the business has improved a bit. I was able to make a profit; however, the profit is still little as it based on the small loan received. Something needs to be done so that I can get a bigger loan and be able to generate more income that will contribute to the generation of more profit and reinvest it back into the business so that the business could grow as the business currently has stagnated. Profit is too small because of the loan which was allocated. The loan allocated to me was seven thousand.

Response 3\# I'm not receiving profit from my business, is not doing well I did not utilise my fund properly. I do not make any profit but still want funds and guidance from Mo EAC to upgrade my business and make more profit. The loan allocated to me was two thousand. 
The excerpts above show that some of the entrepreneurs were making a reasonable profit from their businesses. The profits enabled them to purchase vehicles to transport their business goods, diversify into other businesses such as a kindergarten or welding, as well as selling in other regions. However, some of the entrepreneurs generated a low income and were thus unable to increase their businesses. For those businesses that were unable to expand as anticipated, the profit made was only used to pay for basic needs such as municipal bills, school fees and monthly groceries.

\subsection{Entrepreneurs' Views of the Effectiveness of the ASDSE Project in Terms of Contribution Topoverty Alleviation}

The following comments emerged from the corpus of the entrepreneurs' narratives:

Response 1\# The project has contributed to poverty reduction; I was able to pay for the children to study at the University of Namibia (UNAM). I was able to generate money to contribute to burials of siblings and was able transport the deceased siblings from Windhoek to the Northern parts of the country. However the project did not alleviate poverty as the amount of loan given is too small. I could not buy enough stock to expand my business such as operating from bigger open markets. It makes me operate from home as I could not pay rent and make the business visible to more customers and generate more income. The project has helped us with income generation and employment creation, but a lot needs to be done like availing more financial assistance to move people out of poverty, by giving enough funds and coming up with better income generation projects to alleviate poverty. For instance, we want to be able to make hair extension ourselves and hair products but not retailing hair extensions and products, retailing business is also good but the loan should be increased and be accessed to advance education as the current education what we possess is too low to engage in manufacturing.

Response 2\# The purpose of the project is not realized as some people who had been trained did not receive loans, their applications are either with the bank or with the MoE. They've been waiting for so long. They should give loans to the people to start or upgrade their businesses, let the state intervene to help to monitor what the Ministry of Education is doing, perhaps the state will add money so that our brothers and sisters could benefit from what they are supposed to benefit. Currently we cannot apply for any collateral as we unable to come up with convening proposal as result of poor education background.

Response 3\# The project has contributed to poverty reduction, I was able to pay for my children's transport to and from school and boarding school, was also able to pay for my children's transport to and from hospital, was also able to pay for my children's hospital charges when they sick, municipal bills and basic needs however, it did not alleviate poverty as the amount of loan given is too small. I've applied for an additional loan to buy more stock. Let some people go and examine what the Ministry is doing to the applicants so that a strong solution to the problem can be found and the government's goal of poverty alleviation could be realized. However the starting point should be advance education in manufacturing area.

The above excerpts reveal that the ASDSE project has contributed to poverty reduction. The entrepreneurs were able to pay for their children to study at the University of Namibia (UNAM), generate money for burials; transport deceased siblings to the northern parts of the country, pay for transport to school and children's medical bills. However, entrepreneurs explained that the amount of the loan given was small for starting a business and thus needed to be increased. They also noted a lack of commitment by the Ministry of Education officials to communicate the cause of delays in the processing of loan applications. Moreover, some entrepreneurs received training but no loans. This seems to have defeated the whole purpose of the project.

\subsection{Entrepreneurs' Views on the Effectiveness of the ASDSE Project in Terms of Knowledge and Skills Required from the Training Programme}

The beneficiaries' statements regarding the above include the following:

Response 1\# I anticipated to have the skills and knowledge on how to conduct market analysis and business proposal in order to come up with the good business idea, which will help me to have more customers and receive adequate fund to upgrade my business and help me generate more income. I however did not acquire the skills as period was too short. The presenter did not spent enough time as time was limited as it was just one week but every day was a half a day. The train which was provided was in general trading 
and tailoring and but we wanted specific training on meat, jewellery and wood carving processing and ICT.

Response 2\# I was not fully satisfied with the training received on stock control as well as how to use cashbook. I could, however, not master everything as the duration of the workshop/training was short. I'm still available for a refresher course, to learn the easy way of doing cash book as well as balancing the cashbook.

Response 3\# We were not fully satisfied with training provided because some of the concept were too difficult for us and were not explained clearly to us in mother tongue, as we had left school at tender age, and are not fluent in English, people were in such a hurry and it was only for a week. During training people were more focusing on people who understood English, although they weren't in business. Perhaps future training should focus on the same age group and people who have same qualifications should be trained together. Also, there was no training manual available in local languages.

The various skills in which entrepreneurs received training included recording an income, business commitment, interpersonal communication and how to fix prices for items sold. However, they still required knowledge and skills about how to conduct market research and write business proposals.

\subsection{Entrepreneurs' Views on the Challenges to the Effectiveness of the ASDSE Project}

The following comments emerged from the corpus of the entrepreneurs' narratives:

Challenge 1\#: The loan process is too long, it takes too long for the loan to be recommended to the bank within MoE, it goes through too many Departments like DLO office, regional Office then Head Office before reaching FNB (too much red-tape).

Challenge 2\#: The bank requested me to submit the Certificate of Registration of my company and a health certificate from the municipality that was not stipulated when I completed the Business Plan with MOE officials. When I went to municipality for a health certificate, they did not assist me as they needed a building where I was operating from and I didn't have one. Only after lengthy deliberations between officials from $M o E$ and the bank, were they able to resolve the matter: they approve my loan and by the time I had received the loan to buy the groceries for my business, it was late as most people had left for the December holidays. So, it is important to issue loans within a reasonable time.

Challenge 3\#: I was frustrated because of the bank delays. I was always between my home and the bank. I wasted a lot of my time and money and in return, I got a smaller amount of money. If this money was paid on time, I could not have spent much time and money on transport and going to the bank instead of selling groceries at business premises. These things, like today bring the Identity document, tomorrow bring the municipality bill, another day come and re-complete the bank forms have resulted the quotations to expire and they will send you again to get new quotations and by that time, the prices had gone up. I went to the bank more than five times to fill in various information. It took more than 48 months for my loan to be processed.

Challenge 4\#: The bank charges on the loan approved it is too high, 17\%. The bank is milking us, it's too high for micro entrepreneurs.

Challenge 5\#: The loan granted is too little. It did not consider the buying of other materials which are necessary in order for the carpentry project to succeed. For example, you need a tractor to transport timber from the forest to the workshop to be processed.

The above excerpts show challenges to the self-employment programme were related to the long route the loan process took, the screening committee procedures; delays caused by the bank; poor communication between the MOE and FNB and high bank charges.

\subsection{Entrepreneurs' Views on the Possible Support Measures Needed to Improve the Effectiveness of the ASDSE Project}

The following suggestions emerged from entrepreneurs' narratives:

Suggestion 1: MoE should do away with FNB as a stakeholder and approach any other financial institution which is serious with the micro-entrepreneur like Koshi-Yomuti to process loans on time.

Suggestion 2: The MoE should have one ASDSE Coordinating Officer based at the Head Office to help en- 
trepreneurs fill in applications forms rather than at MOE Regional Offices and deal with the bank so that the loan application process could become shorter. The ASDSE Coordinating Officer should be based at the bank or the official from the bank should be based at the MoE Headquarters.

Suggestion 3: For better implementation, they should give the exact amount of loan requested and give better loan amount on the second time after the entrepreneur has finished paying the loan so that one could expand the business to generate more profit. For instance, if I applied for $N \$ 20,000.00$ the bank should give me $N \$ 20,000.00$ and not $N \$ 12000.00$. Also, the bank charges are too high. The bank is charging 15 percent plus $2 \%$ prime rate; together they charge $17 \%$. This needs to be reduced.

Suggestion 4: Link the ASDSE project to other ministries like Ministry of Gender and Child Welfare and other ministries which issue grants, where the ASDSE beneficiaries could top up with their loans so that one could get free funds to upgrade our businesses.

Suggestion 5: The grace period should be at least extended to six months to allow entrepreneurs to sell and expand before starting repaying back their loans. Unlike now where you only get the loan this month and the next one you are expected to start repaying back.

The above excerpts seem to fault the Ministry of Education, saying that not much was being done to approach other financial institutions to provide loans. Some of the support measures put forward include calling on the head office to appoint a coordinator for the ASDSE project and that agents should help the entrepreneurs to complete the business plan questionnaires. The comments also call for improvements in the ASDSE project by ensuring that entrepreneurs received the exact amounts they requested. They further suggest the need to grant a grace period of six months to allow entrepreneurs to start selling and expanding before they have to start paying back their loans.

\section{Discussions}

\subsection{Entrepreneurs' Views on the Effectiveness of the ASDSE Project in Terms of Profits Generated from Business Activities}

The participants identified some ASDSE benefits in terms ofprofits generated from business activities. Based on the data presented in the empirical part of the report, it can be concluded that profit earned enabled beneficiaries to do the following:

- Purchase vehicles to transport business goods.

- Diversify by establishing other business such as kindergartens and welding. This seems to suggest the benefits of the ASDSE project were creating jobs and generating income for the unemployed and under-employed adult population of Namibia.

However, it seems that some beneficiaries did not make much profit. The reasons cited for this were small loans received and inadequate funding of projects. This seems to have denied some entrepreneurs the opportunity to increase their stock and expand their businesses.

\subsection{Entrepreneurs' Views on the Effectiveness of the ASDSE Project in Terms of Contribution to Poverty Alleviation}

It can be concluded that that the ASDSE project contributes to poverty reduction because:

- It provides finances to pay for the entrepreneurs' children to study at the University of Namibia;

- It provides finances which can be used to contribute to the burials of their siblings;

- It provides finances to transport their deceased siblings from Windhoek to the northern parts of the country;

- It provides finances to pay for children's transport to and from school/boarding school;

- It provides finances for their children's transport to and from hospital;

- It provides finances for their children's hospital fees when they were ill;

- It provides finances to pay municipal bills and for basic needs.

\subsection{Entrepreneurs' Views on the Effectiveness of the ASDSE Project in Terms of Knowledge and Skills Acquired or Not Acquired from the Training Opportunities Provided}

The study reveals that the training provided entrepreneurs with skills to run and manage their businesses. This 
enabled them to record income and calculates expenditure on living expenses and other cost-related issues. It also enabled them to acquire communication and interpersonal skills which are essential for interacting with their customers.

Entrepreneurs listed aspects of knowledge and skills which they needed but did not acquire from the training they had attended. These are:

- Knowledge and skills in developing business proposals.

- Knowledge and skills on how to conduct market research.

- No training manuals were available in local languages.

It seems that the ASDSE beneficiaries were in need of knowledge and skills for developing business proposals so that they could convince banks and other micro-finance institutions to assist them. Other skills and knowledge areas which were lacking in the ASDSE project were those pertaining to engaging in market research, which was needed to enable entrepreneurs to stock the right commodities that would attract customers. Moreover, the participants expressed a concern that the duration of the training was too short to master the skills needed to manage a business.

\subsection{Entrepreneurs' Views on the Challenges to the Effectiveness of the ASDSE Project}

The entrepreneurs revealed a number of challenges. Based on the empirical data these are the following:

- Red-tape. This pertains to excessive bureaucracy and devotion to official rules and procedures.

- The long route taken to process loans, Screening Committee procedures, delays caused by FNB.

- Poor communication between the Ministry of Education, Arts and Culture and FNB. Entrepreneurs were frustrated with FNB, which requested them to present different documents during each visit. The majority of the participating entrepreneurs went to the banks more than five times and in that process lost business. They were not asked to give the correct information or documents needed at the outset in order to expedite the processing of their loan application. This resulted in the processing of loans at FNB taking between eight months to two years.

Weaver [18] also argues that even where directives and requirements are clear, problems may arise as implementers fail to comprehend fully what is expected of them. Kasokonya [19] asserts that implementers need to be capacitated in timeline issues and target compliance in order to achieve the long-term plan for development outlined in Namibian Vision 2030 [20]. Moreover, the situation described above goes against the Memorandum of Understanding (MoU) between the Ministry of Education, Arts and Culture and FNB. The MoU stipulates that if the ASDSE beneficiary is recommended to get a loan, FNB is expected to finalize the processing of the loan in less than two weeks.

\subsection{Entrepreneurs' Views on the Possible Support Needed to Improve the Effectiveness of the ASDSE Project}

Based on the data presented in the empirical part of the report, the following are some of the measures suggested:

- The Ministry of Education must do more regarding the matter of financial institutions not processing the loans on time.

- The Ministry must approach another financial institution which may help the entrepreneurs on time. One such financial institution is Koshi-Yomuti (Financial System Development Services, FIDES Bank). According to the ASDSE beneficiaries, Koshi-Yomuti provides loans to the unemployed and under-employed within two weeks, as opposed to FNB which takes two years.

- The Ministry of Education must have one ASDSE coordinating officer based at the head office to help entrepreneurs complete application forms, rather than at the MoEAC regional offices, and negotiate with the bank so that the loan application process is shortened.

- The Ministry of Education should give the exact amount of the loan requested.

- The Ministry of Education must give better loan amounts after the entrepreneur has finished paying off the first loan so that he/she can expand the business to generate more profit.

- Ministry of Education officials need to link the ASDSE project to other ministries like the Ministry of Gender and Child Welfare and others which issue grants, where the ASDSE beneficiaries could top up their loans so that they could get free funds to upgrade their businesses. It is important that organisations such as 
the ASDSE and FNB which issue training and loans for empowerment and poverty alleviation work handin-hand to secure grants to help serve the poor. They should arrange mechanisms to improve the technical and business skills of the poorest through training and loan utilisation.

- Organisations in charge of training and grants/loans need to take more care to ensure that income-generation activities of their loan recipients are profitable and loan products are appropriate, otherwise loan recipients may need to convert what they have saved as goods into cash to repay their loans, thus depriving themselves further.

- Participants in this study uttered the view that the grace period of one month was too short. It should be extended to at least six months to allow entrepreneurs to sell and expand before starting to repay their loans, unlike the present situation where the loan is given this month and the recipient is expected to start paying back immediately the following month.

\section{Recommendations}

The following recommendations are made with a view of contributing to the improvement of the effectiveness of the ASDSE project implementation and management:

\subsection{Recommendations to the Ministry of Education, Arts and Culture}

- Consideration should be given to revising the amounts of loans granted to prospective entrepreneurs in order to meet the demands for required ASDSE resources for its successful implementation.

- Attention should be given to the beneficiaries' ideas as outlined in the section relating to possible support needed to improve the effectiveness of the ASDSEproject.

- The ASDSE project should be designed to alleviate poverty, curb unemployment and provide skills needed. This can be done by immersing entrepreneurs fully into the business world and all its activities, such as pricing, stock-taking, profit-making, banking, marketing and proper business management skills.

- The participants need to be assisted with marketing. The Ministry of Education should secure space for them at annual trade fairs because this offers opportunities to market their products, which would ensure the availability of customers throughout the year rather than on a seasonal basis. Marketing and entrepreneurial orientation and skills for business owners would, among others, possible solutions for emerging problems in entrepreneurship.

\subsection{Recommendations to the Directorate of Adult Education}

- A reasonably long, uninterrupted period of training for entrepreneurs for them to obtain the required knowledge and skills necessary to run their businesses successfully is recommended. Findings indicate the training period for entrepreneurs is too short and some of the crucial aspects, such as completing the Business Questionnaire Plan (BQP), writing business proposals, marketing strategies and stock-taking techniques were not mastered.

- Advanced training should be offered to Education Officers in charge of training and supervising ASDSE trainees and beneficiaries.

- The ASDSE projects should be designed to alleviate poverty, curb unemployment and provide the skills needed. This can be done by immersing entrepreneurs fully into the business world and its activities, such as pricing, stock-taking, profit-making, banking, marketing and proper business management skills.

\subsection{Recommendations to First National Bank of Namibia}

- Participants in this study expressed the view that a grace period of one month was too short. It should be extended to at least six months to allow entrepreneurs to sell and expand before starting to repay their loans, unlike the present situation where the loan is given this month and the recipient is expected to start paying back immediately the following month.

- The FNB needs to speed up the process of granting loans to applicants.

\section{Conclusion}

This paper has presented entrepreneurs' views of the effectiveness of the Adult Skills Development for Self- 
employment project in the National Literacy Programme in the Khomas Education Region of Namibia. The answers to the four research questions seem to point to the ASDSE project being effective in terms of knowledge and skills provided and in terms of contributing to poverty alleviation. However, significant components of advanced training need to be incorporated to make it more effective in terms of knowledge and skills required. The challenges and support measures to improve the effectiveness of the ASDSE project were outlined but these necessitate a holistic effort by the Ministry of Education, Arts and Culture, Ministry of Gender, and Child Welfare, the First National Bank of Namibia and other financial institutions. On the whole, if the ASDSE project is to become fully effective, these entities must revisit some of the strategies, taking into account the views of entrepreneurs as outlined in this paper.

\section{References}

[1] Amukugo, E.M. (1993) Education and Politics in Namibia: Past Trends and Future Prospects. Gamsberg, Windhoek.

[2] Cohen, C. (1994) Administering Education in Namibia: The Colonial Period to the Present. Namibia Scientific Society, Windhoek.

[3] UNESCO (2008) EFA Global Monitoring Report: Overcoming Inequality—Why Governance Matters. Unesco, Paris.

[4] Central Bureau of Statistics (2010) An Atlas of Namibia’s Population: Monitoring and Understanding Its Characteristics. Central Bureau of Statistics, Windhoek.

[5] Ramarumo, M. and McKay, V. (2008) Evaluation of the National Literacy Programme: Final Report. Ministry of Education: Directorate of Adult Education, Windhoek.

[6] Republic of Namibia (2005) Constitution of Namibia. Ministry of Information and Technology Communication, Windhoek.

[7] Republic of Namibia. Directorate of Adult Basic Education (2003) ASDSE Annual Report. Ministry of Basic Education, Sport and Culture, Windhoek.

[8] Tonin, C., Ricoveri, A. and Zaire, M. (1997) Training and Micro Credit for Labour Creation in Namibia: The Experience of the Adult. Skills Development for Self-Employment Pilot Project. CISP/DABE, Windhoek.

[9] Republic of Namibia. Directorate of Adult Basic Education (1998) ASDSE Annual Report. Ministry of Basic Education, Sport and Culture, Windhoek.

[10] Republic of Namibia. Directorate of Adult Basic Education (2008) ASDSE Annual Report. Ministry of Basic Education, Sport and Culture, Windhoek.

[11] Ministry of Education (2006) Education Sector Improvement Programme. Programme Development Phase. Ministry of Education, Windhoek.

[12] Leedy, P.D. and Ormond, J.E. (2010) Practical Research Planning and Design. 9th Edition, Pearson Education International, Boston.

[13] Lodico, M.G., Spaulding, D.T. and Voegtle, K.H. (2006) Methods in Educational Research: From Theory to Practice. John Wiley, San Francisco.

[14] Gays, L.R., Mills, G.E. and Airasian, P. (2003) Education Research: Competencies for Analysis and Application. Pearson, Boston.

[15] MacMillan, J.H. and Schumacher, S. (2001) Research in Education. A Conceptual Introduction. 5th Edition, Longman, Boston.

[16] Gall, M.D., Gall, J.P. and Borg, W.R. (2006) Educational Research: An Introduction. Pearson Education, Boston.

[17] Hamunyela, M.N. (2008) A Critical Analysis of Parental Involvement in the Education of Learners in Rural Namibia. Unpublished Thesis, University of Pretoria, Windhoek.

[18] Weaver, R.K. (2010) But Will It Work? Implementation Analysis to Improve Government Performance. http://www.brookings.edu/ /media/research/files/papers/2010/2/implementation-analysis-weaver/02_implementation_ analysis_weaver.pdf

[19] Kasokonya, M.S. (2007) An Investigation of How Members of a School Board Perceive and Experience Their Roles in a Secondary School in the Rundu Education Region of Namibia: A Case Study. Unpublished Master's Thesis, Rhodes University, Grahams Town.

[20] Government of the Republic of Namibia (2004) Namibia Vision 2030, Policy Framework for Long-Term National Development. Office of the President, Windhoek. 


\section{Submit or recommend next manuscript to SCIRP and we will provide best service for you:}

Accepting pre-submission inquiries through Email, Facebook, Linkedin, Twitter, etc A wide selection of journals (inclusive of 9 subjects, more than 200 journals)

Providing a 24-hour high-quality service

User-friendly online submission system

Fair and swift peer-review system

Efficient typesetting and proofreading procedure

Display of the result of downloads and visits, as well as the number of cited articles

Maximum dissemination of your research work

Submit your manuscript at: http://papersubmission.scirp.org/ 